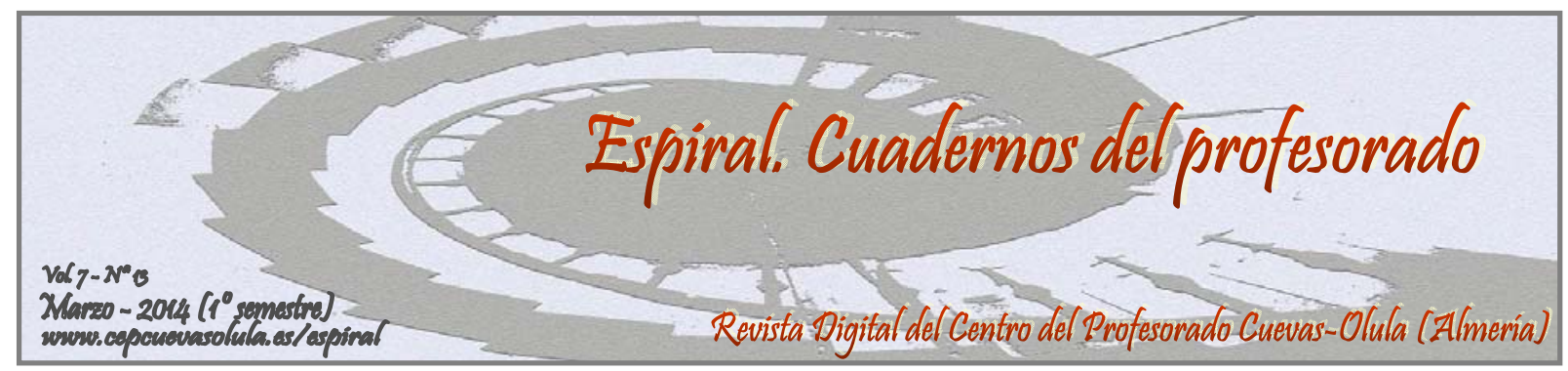

\title{
PROPUESTAS DIDÁCTICAS MUSICALES PARA TRABAJAR INTERCULTURALMENTE EN ESO: LA MÚSICA POP DE MESTIZAJE
}

\section{MUSIC TEACHING SUGGESTIONS FOR WORKING INTERCULTURAL IN SECONDARY EDUCATION: THE POP MUSIC OF MISCEGENATION}

\author{
María del Mar Bernabé Villodre
}

UCAM - Universidad Católica de Murcia, España

\begin{abstract}
RESUMEN: Este artículo tiene como objetivo principal mostrar cómo la clase de Música de Secundaria puede contribuir al desarrollo social y personal del educando en contextos pluriculturales, al tiempo que permite interiorizar conceptos puramente musicales. En este sentido, se muestran algunas de las actividades que se desarrollaron en diferentes cursos académicos en aulas de Secundaria de la Región de Murcia y de las Islas Baleares, con las que se pretendía garantizar la convivencia del alumnado y el establecimiento de lazos socio-afectivos que les llevasen a una positiva relación intercultural, siempre asegurando también el aprendizaje específico musical. Se consideró que debían revisarse las propuestas basadas en la música tradicional para acercar las diferentes culturas al alumnado y ofrecerles actividades desde una música realmente cercana para ellos, pero sin olvidar el elemento tradicional; de manera que, se seleccionó la música de Macaco que ofrecía un enriquecedor mestizaje. Mediante una metodología muy activa y participativa caracterizada por el espíritu cooperativo en cada una de las actividades tradicionales del aula musical (audición, improvisación, composición, análisis), se pudo comprobar cómo este tipo de música "pop-mestiza” permitía trabajar los contenidos más específicamente musicales, además de que posibilitaba el paso de la coexistencia multicultural a la convivencia intercultural.
\end{abstract}

Palabras clave: música, educación intercultural, competencia social y ciudadana.

ABSTRACT: This article's main objective is show how the Secondary School music class can contribute to social and personal development of learners in multicultural contexts, while allowing purely internalize musical concepts. Here, are some of the activities that took place in different academic courses in Secondary classrooms in the Region of Murcia and the Balearic Islands, with which they intended to ensure the coexistence of students and establishment of social-emotional ties to them could lead to positive intercultural relations, always ensuring specific learning also musical. Was considered to be revised proposals based on traditional music to bring different cultures to students and offering activities from a music really close to them, but without forgetting the traditional element, so that was selected Macaco music featuring a enriching miscegenation. Through a very active and participative methodology characterized by the cooperative spirit in each classroom traditional musical activities (listening, improvisation, composition, analysis), we noted how this kind of music "pop-mixed" content allowed to work more music specifically, besides that allowed the passage of multicultural coexistence to intercultural coexistence.

Key words: Music, intercultural education, social and civic competence. 
Bernabé Villodre, M. M. (2014). Propuestas didácticas musicales para trabajar interculturalmente en ESO: la música POP de mestizaje. Espiral. Cuadernos del Profesorado, 7(13), 59-70. Disponible en: http://www.cepcuevasolula.es/espiral.

Fecha de recepción: 28/09/2013

Fecha de aceptación: 12/11/2013
Enviar correspondencia a: elchesociologia2@gmail.com

\section{1.- INTRODUCCIÓN}

El siglo XX fue especialmente significativo para la política educativa española, que comenzó a reflejar la importancia de dar respuesta a las necesidades del alumnado hijo de inmigrantes que cada vez era más numeroso en el país, al tiempo que debía mostrar las diferentes culturas propias de cada región del país. Pero, ante todo, las referencias legislativas no podían dejar de recoger el hecho de que el proceso educativo, más allá de cuestiones multiculturales o interculturales, debía comprenderse como global, es decir, que los docentes debían educar y no enseñar, que debían educar en valores (Olaya, 2002).

La legislación educativa surgida a raíz de la consolidación de la democracia vendría a asentar las bases de las futuras políticas educativas que pretendían garantizar una educación de calidad y en igualdad para todo el alumnado, fuese cual fuese su procedencia. Como acercamiento a las realidades culturales propias del territorio nacional, se incluyó en el currículo la música tradicional de cada comunidad autónoma; hecho que contribuiría a facilitar la comprensión de las otras músicas tradicionales del resto del mundo. Sin embargo, ese acercamiento a otras culturas mediante la música resultó ser bastante menos beneficiosa de lo esperado (Martín, 2009), cuestión debida, principalmente, a factores como la escasísima formación docente en música tradicional y a las confusas propuestas didácticas denominadas interculturales con demasiada ligereza.

Las escasas relaciones entre las diferentes culturas variaban mucho de una zona de trabajo a otra: por ejemplo, se pudo comprobar cómo en el centro concertado de Murcia, el alumnado de China no se relacionaba más que con los de su mismo origen, mientras que en los centros públicos de Baleares, el alumnado se relacionaba socialmente sin complicaciones, incluso se habían formado grupos de amigos pluriculturales. El carácter de los isleños ante el fenómeno migratorio era, por tanto, totalmente diferente al de los peninsulares: el turismo mucho mayor había provocado cambios en su mentalidad. Así pues, la inmigración entre el alumnado joven no era vista como algo negativo; ahora bien, las opiniones de los adultos eran diferentes porque sino no se podrían comprender los problemas raciales vividos entre gitanos e inmigrantes del cuerno de África. Y, precisamente, para hacer extensible al resto de la sociedad ese clima de convivencia e intercambio que se respiraba en los centros de Baleares donde se desarrolló nuestra actividad docente, se consideró necesario trabajar con material cercano a ellos, más que con música tradicional que no era próxima a ellos, realmente. Aunque, la mayor o menor relación entre culturas en los dos centros de Baleares variaba: uno de los centros era de una población menos habitada y el otro era mucho mayor y con más cantidad de inmigración con menor poder adquisitivo. Este tema económico parecía determinar las relaciones entre el alumnado, lo que lleva a suponer que más que problemas de relaciones culturales se dan problemas de relaciones basadas en "cuánto tienes".

Estas situaciones presenciadas vinieron a corroborar las palabras de Riviére (2009) sobre cómo la influencia de la economía es más fuerte que la de la cultura, ya que se considera que esos países en vías de desarrollo no detentan un importante patrimonio cultural; aunque, puedan poseer testimonios de grandes culturas más adelantadas que las presentes en este territorio en la misma época.

El alumnado de Murcia necesitaba practicar la interculturalidad, ser conscientes de las grandes similitudes y de la riqueza de la diferencia. Había que evitar que compartiesen posturas con sus familias que no habían convivido desde su nacimiento con la pluriculturalidad tan fuerte desde la década de los '90 del pasado siglo y estas primeras del siglo XXI. Y, en Baleares, debían promoverse 
actividades para reconocer las diferencias y extender sus posturas al otro agente implicado en el proceso educativo: las familias. Sólo contando con su apoyo y entendimiento, se podría conseguir una situación intercultural más allá del centro educativo.

Se consideró que las clases de música de $2^{\circ}$ y $3^{\circ}$ de ESO debían destinarse exclusivamente a promover unos valores que fácilmente podían considerarse universales, al ser fruto de la evolución cultural del ser humano (Vila, 2005). Al mismo tiempo que se podían trabajar valores interculturales, gracias al carácter eminentemente práctico y cooperativo del proceso de enseñanza/aprendizaje musical, no se dejaban de trabajar los objetivos específicamente musicales, pero desde una perspectiva cultural comparada que contribuyese al refuerzo de la interculturalidad y sus valores y características.

Ante la pluriculturalidad existente en los tres centros y, al mismo tiempo, la universalidad de los valores que se quería transmitir, se consideró que la mejor forma de educar en igualdad a esa diversidad cultural para que lograsen establecer lazos con aquellas minorías culturales menos conocidas, era utilizando la música tradicional. Pero, ésta sería trabajada desde las referencias incluidas en la música moderna y, en concreto, desde la música del grupo Macaco que presenta múltiples influencias culturales gracias a la pluriculturalidad de sus miembros. De manera que en este artículo se ha pretendido mostrar cómo las actividades musicales más tradicionales tales como la audición o la improvisación, pueden convertirse en importantes herramientas educativas interculturales gracias a la utilización de la música de Macaco, que mezcla ritmos y melodías tradicionales de otras partes del mundo con elementos pop españoles. Así se consiguió una aproximación al aprendizaje del lenguaje musical, al tiempo que se trabajaban los valores interculturales tan necesarios para el avance social armonioso.

La mejora del clima del aula, el hecho de que el alumnado aprendiese a relacionarse con normalidad, demostró la importancia de abordar la actividad musical como instrumento educativo intercultural y no sólo educativo musical específico. Este hecho llevó a la realización del presente artículo, dado que para el abordaje de la interculturalidad en el aula musical, la bibliografía actual muestra un uso más habitual de la música tradicional de diferentes partes del mundo que el alumnado suele recibir con gran extrañeza; mientras que los elementos tradicionales extracomunitarios presentes en la música de Macaco, son aceptados con normalidad. Esto supuso el punto de partida para un trabajo específico de los mismos que permitió comprender y razonar éstos, con el consiguiente aporte para la mejora de la convivencia y la consecución de la interculturalidad.

\section{2.- ORIGEN DE LA EXPERIENCIA}

En el centro concertado de la Región de Murcia se observó cómo el alumnado inmigrante de cierto poder adquisitivo, pese a esa fuerza económica, no se relacionaba con el alumnado autóctono. Esta situación, llevó a plantear actividades que mejorasen la socialización, las relaciones entre el alumnado, como primer paso para trabajar valores interculturales que diesen paso a una convivencia intercultural. Era cierto que se coexistía pacíficamente, pero la falta de diálogo, de situaciones de intercambio, no hacen más que ocultar problemas de hondo calado que podrían explotar en cualquier momento; es decir, que una coexistencia multicultural podía terminar por desembocar en problemas de más fácil o difícil solución, resultado de la inexistencia de diálogo, de comunicación, entre los compañeros del aula. Debido a toda esta situación, se consideró que la interacción cultural que promueve la educación intercultural era la mejor forma de prevenir actitudes racistas y xenófobas (Leiva, 2011), que sólo se esconderían con modelos educativos multiculturales porque éstos no promueven ni el diálogo ni la interacción cultural.

Como oposición a la situación de Murcia, cuando se comenzó a trabajar en institutos públicos de las Islas Baleares (uno de una población pequeña y más rica y otro de una población más grande y con diferentes poderes adquisitivos), se pudo comprobar cómo las relaciones entre culturas fluían. No se limitaban a coexistir, a compartir espacio, sino que los grupos de amigos eran pluriculturales; ahora bien, se observaron grandes diferencias entre un centro y otro, y entre las culturas que conformaban cada grupo pluricultural. 
Todo esto, llevó a plantear una modificación de las actividades trabajadas en Murcia para responder a la nueva situación vivida en Baleares. Con este hecho, se muestra cómo el docente debe adaptarse y readaptarse constantemente a la nueva situación pluricultural característica de las diferentes zonas donde desarrolle su tarea docente. Al tiempo que, se debe ser consciente de que, pese a la readaptación porque la forma de contactar las culturas es diferente en cada zona, se comparte una etapa educativa (última etapa obligatoria) y una etapa vital (la adolescencia) que debe encaminarse a garantizar la incorporación del alumnado a su sociedad. En definitiva, además de ciudadanos socialmente competentes, se debía preparar ciudadanos culturalmente competentes para relacionarse con otras culturas y compartir una nueva, fruto de sus interacciones; y, a todo esto, debía sumarse la importancia de ofrecer actividades que llegasen a implicar a todos los agentes importantes en el proceso educativo.

En este contexto, la enseñanza artística musical fue comprendida como un punto de encuentro propiciador de la expresión y la comunicación entre culturas, además de enriquecedora para la formación integral del educando (Conejo, 2012). Se consideró que la "renuncia” al libro de texto o su limitación a determinados momentos (con un uso diferente) posibilitaba un planteamiento más flexible y creativo que se adaptaba mejor a la realidad del aula, de acuerdo con Vicente (2010). Es decir, que no era más que un punto de apoyo, de partida, para el desarrollo de actividades alejadas del mismo, que tenían como principal objetivo el desarrollo de una convivencia intercultural.

\section{3.- OBJETIVOS}

El presente artículo pretende demostrar cómo las actividades musicales interculturales basadas en la utilización de la música "pop-mestiza” de Macaco, propuestas en distintos centros de Educación Secundaria, permitieron una mejora del clima social del aula y, al mismo tiempo, la comprensión de contenidos puramente musicales. Esta intención vino determinada porque tras la búsqueda de actividades musicales que pudiesen realizarse en contextos pluriculturales, se observó que todas ellas mencionaban casi exclusivamente la música tradicional como muestra musical más importante para el trabajo de la interculturalidad (cuando no se mencionaba la multiculturalidad comprendida como aquella). Sin embargo, la experiencia con este tipo de música en el aula, mostró cómo al alumnado le costaba comprenderla, incluso aquel procedente del lugar de la música escuchada la veía extraña; así el proceso educativo intercultural se veía más lento y alejado del alumnado. Entonces se consideró la posibilidad de utilizar la música de Macaco, que incorporaba tantos ritmos, melodías e incluso instrumentos de otras culturas diferentes a la occidental (española, en concreto), para lograr un acercamiento entre culturas; de esta manera se estaba intentando mostrar cómo este tipo de música debía convertirse en una muestra de lo que está sucediendo socialmente, es decir, de cómo la música tradicional no occidental se puede encontrar incorporada a otras músicas occidentales y, por tanto, serán ellas las que faciliten el conocimiento de otras culturas en el aula de Secundaria.

Entre los objetivos de las actividades realizadas durante la labor docente en Secundaria, principalmente, se pretendía garantizar unas relaciones culturales con la mayor igualdad posible, esto es, posibilitando la comprensión de los elementos característicos de cada cultura desde la reflexión comparada de la propia.

También se buscaba fomentar el diálogo cultural desde actividades musicales cooperativas y de espíritu colaborativo, para establecer relaciones de dependencia entre ellos. El colaborativismo ayudará a fomentar espacios de diálogo en el aula (Vila, 2009), por lo que debe comprenderse como elemento fundamental que caracterizará las actividades. Y esos vínculos entre el alumnado serán imprescindibles para lograr la interculturalidad en el centro educativo; puesto que ésta debe considerarse como un paso educativo de relevancia social (Leiva, 2011) para que las diferentes culturas presentes en la sociedad puedan convivir en igualdad y respeto.

Y, finalmente, se quería presentar el arte musical como documento esencial de la vida de una cultura (modificando las consideraciones de Schnaase, citado en Venturi, 2004, sobre el arte en general) y, por tanto, como común, compartido, construido conjuntamente, comprensible por todos, influido mutuamente... 


\section{4.- METODOLOGÍA}

Se incluye una breve reflexión sobre la literatura existente y cómo se ha intentado mostrar lo imprescindible de partir de un espíritu cooperativo para enfocar las distintas actividades tradicionales del aula musical, de manera que se considere posible la adquisición de la interculturalidad.

A continuación, se detallan los diferentes pasos seguidos durante la experiencia práctica y la justificación que se ha dado a cada uno de ellos, siempre teniendo en cuenta que el punto de partida del presente artículo (uso de la música "pop-mestiza” como más próxima al alumnado que la tradicional más pura) no es una consideración habitual en la bibliografía actual.

Tanto en Murcia como en Baleares se siguieron los mismos pasos en cuanto a la concreción de las herramientas o instrumentos más adecuados para seleccionar y preparar las actividades más convenientes para el contexto pluricultural. Se partió de la consideración de que, ante todo, se pretendía desarrollar la competencia social y ciudadana de tipo intercultural, fácilmente realizable gracias al hecho de que en esta asignatura todo el alumnado participaba de las mismas actividades con una clara intencionalidad educativa global común a todas las materias de Secundaria (Bosch, 2002); y todos los alumnos se relacionaban (Navas, Iborra y Sampascual, 2007) entre sí, en mayor o menor medida, gracias a la dependencia de las actividades musicales (grupales).

Entonces, si la clase de música se comprendía como punto de encuentro, como lugar que permitía al educando la construcción de su experiencia (Touriñán y Longueira, 2010), el profesorado tendría que entenderlo como un lugar en el cual comprender dónde estamos para poder entender "al otro” (García-Durán, 2001); es decir, la clase de música como espacio de conocimiento propio, de reflexión, para empezar a conocer y respetar la alteridad, gracias a la gran cantidad de elementos compartidos y al enriquecimiento que supone la diferencia.

En primer lugar, se prepararon actividades destinadas a la interpretación instrumental y vocal, porque éstas implicaban respetar al otro ya que se podían poner en su lugar (Sanfeliu y Caireta, 2005). Además, ésta supone el establecimiento de unos lazos de dependencia con "el otro" para llegar a obtener un producto final común que contribuya a unirlos más. Así, quedaba comprobado que la interpretación era un medio adecuado para trabajar interculturalmente en el aula, puesto que la educación intercultural supone el respeto de la alteridad y la integración grupal, que permite la música gracias al compartir cantando y tocando instrumentos musicales (Conejo, 2012).

En segundo lugar, las actividades de audición musical se plantearon con un alto grado de participación y acción del alumnado. Ante todo, se quería evitar caer en prácticas auditivas multiculturales que se limitasen a escuchar música de diversa procedencia, con el único objetivo de garantizar el conocimiento de otras realidades culturales, pero sin intercambio ni reflexión propia. Es decir, que se pretendía estimular el análisis de elementos conocidos y la reinterpretación de éstos, si se descubrían similitudes. Este enfoque intercultural permitiría repensar la propia cultura, una característica más del proceso educativo intercultural que era fácilmente aplicable para la educación musical.

En tercer lugar, se consideró la importancia de utilizar actividades de improvisación musical, a pesar de que este tipo de actividades puedan considerarse más características para Primaria que para esta etapa de Secundaria, tal como se puede deducir de una lectura de la legislación vigente. No obstante, este recurso contribuirá a garantizar la construcción conjunta de un producto cultural propio de la microsociedad del aula; y, esta idea debía extrapolarse a la macrosociedad exterior. Es decir, que gracias a las actividades de improvisación se pretendía trabajar la creatividad del alumnado y la música con un lenguaje más cercano que ellos mismos iban a crear; así, podrían reflexionar y repensar su propia cultura. Básicamente, garantizaría un conocimiento más profundo de sus características culturales, aquello que puede caracterizar la de otros y cómo podemos obtener algo común y/o compartido. En la educación intercultural la base está en el diálogo y el intercambio, precisamente, los dos elementos que se pueden trabajar con la improvisación musical, y que permitirán comprender al otro y reconocerlo como legítimo (Vila, 2005), de ahí la importancia de sus actividades. 
En penúltimo lugar, se consideró importante promover actividades de composición en plan cooperativo, para invitarlos a reflexionar sobre su cultura musical propia y sobre la "del otro". Desde la composición se podrían acercar a las características de este producto cultural (musical) y repensarlas, reflexionar sobre ellas para conseguir un nuevo resultado que mostrase su evolución cultural. Ante todas estas posibilidades de la composición, se llegó a la conclusión de que debían desarrollarse actividades así; debido a que, igual que sucede en la interculturalidad, que invita constantemente a repensar la cultura y a construir una nueva compartida gracias al conocimiento, el respeto y el intercambio, la composición musical como obra artística transformaría sus conciencias (Céspedes, 2009) culturales.

Y, finalmente, ya que la legislación menciona la introducción al análisis de las partituras musicales, debían promoverse actividades de este tipo. Gracias a este tipo de actividades centradas en la comparación entre piezas de diferente procedencia pero de la misma época, el estudio de las diferentes músicas del mundo debía resultarle más entretenido al educando y éste reflexionaría sobre las importantes similitudes entre músicas de procedencia culturalmente diversa. De acuerdo con Arenas (2009), ese estudio de la música más aparentemente teórico, garantizaría la comprensión de los intereses y orígenes comunes entre las diversas culturas que han dado lugar a la música actual (moderna, clásica o tradicional).

De manera que, esta asignatura pasaba a convertirse en el centro neurálgico de la actividad intercultural. Aunque, eran tantos los estilos y tipos de música que la incompleta formación del docente en todas ellas complicaba el trabajo en el aula musical (Bravo y De Moya, 2006). Este hecho supuso la lectura de gran cantidad de bibliografía específica de la música no occidental y de la música tradicional de diferentes zonas del mundo, además de la música moderna de las mismas.

\section{5.- PROPUESTAS DIDÁCTICAS DESARROLLADAS}

Díaz e Ibarretxe (2008) consideran que los materiales del docente tienen que adaptarse a la vida cotidiana del aula. Así pues, el profesorado de música emprende sus tareas con gran "facilidad" porque la música de cada etapa es igual que la de la anterior, es decir, se combinan los mismos elementos de formas diferentes para obtener una nueva sonoridad, que puede repetirse en posteriores ocasiones. De hecho, su practicidad (Navas, Iborra y Sampascual, 2007) refuta esa interpretación de materia privilegiada.

Las canciones de Melendi, Macaco, Bisbal... son muy simples, muy en la línea de los esquemas introducidos en el Clasicismo musical; con la inclusión de giros armónicos y melódicos de la música tradicional de sus respectivas comunidades y lugares de origen. La cuestión es que sí se puede hacer próxima esta materia a ese alumnado culturalmente diverso que se mueve por interés hacia el objeto de aprendizaje; de manera que, se debe promover el uso de una música atractiva que les permita comprender la música como un proceso vivo de creación (Sanfeliu y Caireta, 2005), es decir, en constante cambio gracias a sus propias aportaciones y a las “del otro".

Puesto que se comprobó que los casos de alumnado extranjero desconocedor de su cultura musical eran tan numerosos como los del alumnado autóctono que desconocía su música tradicional, como también había demostrado Arévalo (2009), se consideró que debía promoverse un acercamiento a su cultura y a otras culturas desde tipos de música diferentes, como primer paso. En este sentido, ya que la música moderna presenta tantas fusiones armónicas, rítmicas, e incluso de movimiento en los bailes que puedan llevar asociados, se consideró que podía convertirse en una herramienta ideal para trabajar interculturalmente: un buen ejemplo sería la canción "Waka waka" de Shakira, en la que ritmos, palabras y movimientos muestran claras influencias de la música tradicional africana. Es decir, se quería huir de la interpretación de música tradicional desde una perspectiva multicultural, que no fomentaba el intercambio ni el diálogo, y que enmascararía un racismo y una xenofobia latentes que terminarían estallando; pero, si las actividades musicales partían de análisis comparados que invitasen a la reflexión, a repensar, podrían considerarse un éxito intercultural.

Si bien, la música tradicional debe incluirse en el currículo para garantizar la heterogeneidad cultural del currículo, debería replantearse la forma de trabajarla, para acercarla al alumnado que no se 
siente nada próximo a ésta. Ante todo, debería mejorarse la formación del profesorado en este tipo de música para que no transmita una idea deformada (Martín, 2009); y, al mismo tiempo, debería tenerse en cuenta que el alumnado de Secundaria prefiere la música popular urbana o moderna a la música tradicional (muchas veces denominada popular), como muestran las investigaciones de Herrera, Cremades y Lorenzo (2010). Sin embargo, se trabaje con un tipo de música u otro, la educación musical debe promover la adopción de nuevos criterios culturales de valoración (Bravo y De Moya, 2006), de gran utilidad para la garantizar situaciones interculturales.

Se realizó una selección del repertorio de Macaco y se elaboraron actividades que permitiesen trabajar valores interculturales, así como las características de otras músicas del mundo. Se eligió este grupo porque muestra en sus letras la realidad social actual, gracias a unas letras comprometidas, con fusión de ritmos. Precisamente, a través de estas canciones se comprobó cómo educar interculturalmente era una realidad sin necesidad de trabajar exclusivamente la música tradicional. De acuerdo con Arévalo (2009), la educación debía partir del entorno y contexto del alumnado, es decir, aquello que se va a transmitir debe resultarle cercano para que pueda asumir ese nuevo conocimiento e incorporarlo como propio.

Del amplísimo repertorio de Macaco se seleccionaron aquellas que presentaban una temática social con mensaje intercultural: Moving, Caigan que caigan, Como el agua calé, Crece la voz, Giratutto, Mensajes del agua, Se mueven, Tengo, Todos, y Una sola voz. No obstante, debido a la limitación de espacio, únicamente se han incluido tres de esta selección, aquellas que se han considerado especialmente importantes para garantizar la comprensión de los valores y actitudes interculturales: Moving, Mensajes del agua y Una sola voz.

Una canción muy apropiada para trabajar las influencias entre culturas es Moving, gracias a sus marcados giros flamencos fusionados con el pop. Con esta canción se muestra el enriquecimiento que supone la diversidad de aportaciones a una misma obra musical, cómo éstas pueden dar lugar a una pieza diferente e interesante, y todo ello queda comprobado mediante el vídeo musical realizado para su visionado en programas de videoclips. La interculturalidad se comprenderá, entonces, como una herramienta fundamental para desarrollar integralmente al alumnado (Cobo, Motos, García y Moral, 2009), para enriquecerlo personal y culturalmente.

Puesto que el alumnado de Secundaria ya contaba con mayor nivel de Lenguaje Musical, se consideró útil para reforzar dichos conocimientos, que el alumnado siguiese la audición mediante la partitura de flauta de pico, pero con la letra escrita como si se tratase de una partitura de canto. Lo que debían hacer era marcar en ella aquellos fragmentos que les pudiesen resultar extraños, porque después debían discutir en grupos sus motivos y, también, debían comentar los elementos conocidos mediante posibles relaciones con otras músicas. Básicamente, se quiso conseguir un momento de atención a los posibles elementos "extraños" en la partitura y ver cómo los relacionaban con otras músicas conocidas, al tiempo que las explicaciones de los compañeros les guiasen hacia nuevas relaciones.

Seguidamente, tras esa reflexión, debían tratar de recordar canciones más o menos actuales que les pareciesen similares a la escuchada. La reflexión musical cultural que se les invitó a realizar perseguía el autodescubrimiento de las similitudes más allá de las diferencias. Se quiso mostrar cómo las igualdades están muy presentes, para que éstas llevasen a la apreciación de la diferencia como elemento enriquecedor y necesario para evitar la homogeneidad que impone el proceso globalizador. De acuerdo con Gómez Quintana (2011), se trataría de conocer la sociedad que ha dado esos resultados musicales para relacionarla con la cultura que rodea al alumnado; de forma que, con actividades de este tipo éste llegue a conocer las características del lenguaje musical de otras zonas del mundo y, por tanto, que respete "al otro" tras un proceso de reflexión cultural. Todo esto se vio reforzado por la interpretación colectiva que implica respeto al compañero a la aportación "del otro” y un trabajo de valores interculturales.

Por supuesto, es cierto que cuando se trabajan canciones, las letras resultan complicadas para el alumnado que desconoce la lengua o que no la controla al mismo nivel que un alumno autóctono. No obstante, lo bueno de esta canción es que mezcla pequeños fragmentos en inglés, que 
supuestamente es una lengua más internacional y que en mayor o menor medida es comprendida por casi todo el alumnado, sea cual sea su origen. Este estudio de la letra permitió insistir en el hecho de que la unión hace la fuerza y que dicha unión es evolución para el mundo. Entre los diversos mensajes que se pueden trabajar con esta obra, está la importancia de que la cultura no es un elemento estático, sino que es un producto dinámico resultado de la unión de multitud de elementos de diferente procedencia. De manera que, se puede comprobar que el área musical es el lugar idóneo para el trabajo de los valores (Azorín y Vicente, 2012).

Pero, el trabajo de la letra no podía reducirse a un simple análisis y reflexión individualizada, porque la consecución de la interculturalidad pasa porque el alumnado aprenda a trabajar conjuntamente y para un fin común. Ante esta exigencia de cooperatividad de la interculturalidad, se debía organizar una actividad grupal; así pues, se organizaron grupos de trabajo en los que cada uno tenía que pensar una frase que sintetizase el mensaje general de cada estrofa, que después debía ponerse en común con el resto de grupos. La última parte del ejercicio consistía en que cada uno de los grupos debía buscar imágenes en internet que sintetizasen la interpretación del otro grupo. Con este ejercicio se pretendió que comprendiesen que la música tiene múltiples interpretaciones y que sus significados nunca están cerrados porque es un producto cultural y, por ello, constantemente inacabado.

El trabajo del videoclip de esta canción fue muy interesante porque, además de resultar un momento muy entretenido, recogía la importancia de la fusión entre culturas al ofrecer una visión de distintos cantantes y actores de nacionalidades diversas que bailaban la misma canción, pero cada uno de acuerdo con los diferentes elementos que caracterizan su cultura. Este análisis de movimientos permitió iniciar el camino hacia la comprensión de cómo todas las culturas tienen cabida dentro del arte musical.

Como continuidad del uso de las nuevas tecnologías de la comunicación y la información, con la canción Una sola voz, también se pudieron realizar actividades más interactivas y que contribuyesen a garantizar competencias en estas nuevas tecnologías. Se partió de la visualización del videoclip, en el que aparecen representantes de diferentes grupos urbanos, lo que en sociología se denominan las "tribus urbanas" y de un estudio de la letra que, principalmente, comenta que debemos convertirnos en una sola voz que cante al mismo tempo. Tras unas reflexiones sobre el mensaje que transmitía a cada uno, de forma individual, crearon parejas para buscar información sobre cada uno de esos grupos representados en el vídeo. Para concluir, realizaron una puesta en común que debía procurar enlazarse con la del grupo anterior; de modo que, se lograsen establecer vínculos de igualdad que permitiesen valorar la diferencia como elemento enriquecedor y diferenciador significativo para conservar la heterogeneidad del mundo.

Por supuesto, la actividad más característica del aula musical, intercultural o no, es la interpretación instrumental y vocal. Sobre la interpretación de esta pieza no puede aportarse ningún elemento innovador o especialmente característico, puesto que la propia interpretación musical ya implica la puesta en práctica de diferentes valores interculturales que ya han sido sobradamente comentados a lo largo de estas páginas (respeto a las aportaciones del otro, necesidad de la interpretación del otro, necesidad de conocimiento de la cultura que ha producido dicha obra, etc.). Sin embargo, cuando se trabaja con adolescentes no pueden dejar de comentarse aquellos objetivos que se pretenden con cada una de las actividades; es decir, la justificación de la actividad supondrá la valoración del adolescente como un agente más activo en el proceso de enseñanza/aprendizaje, lo que a su vez reforzará su propia percepción y, por extensión, el respeto al resto de agentes implicados en la actividad.

Otra de las canciones trabajadas permitió acercarse a la interculturalidad desde unas interesantes metáforas: Mensajes del agua. En ésta, el mensaje era lo más interesante para trabajar en el aula: básicamente, el agua del planeta puede llamarse de diferentes formas (mar, océano, río, lago, etc.), pero es agua al fin y al cabo. Es decir, vive dónde sea, pertenece a la cultura que sea, pero eres un ciudadano del mundo que se mueve al mismo ritmo que otro porque la música es universal, es un lenguaje compartido con “otros nombres”, como el agua del planeta. 
Esta obra se trabajó con actividades de cultura musical comparada. Esto es, debían buscar en youtube canciones que presentasen algún elemento en sus títulos o estrofas que hiciese referencia a palabras clave de esta pieza. Esta búsqueda se realizó por parejas y se puso en común en grupos de cuatro que debían ir rotándose para que, al finalizar la clase, todos hubiesen compartido ideas con el resto de parejas de la clase.

De manera que, con actividades de este tipo se logrará un mayor desarrollo de la interculturalidad, desde actividades que potencian la creatividad de pensamiento como oposición a lo homogéneo y como reivindicación de lo diverso (Díez, 2009). Así, una pieza musical moderna no sólo habrá permitido trabajar la interculturalidad, sino también, los distintos elementos constitutivos de esta asignatura. Entonces, de acuerdo con nuestra experiencia, es posible educar interculturalmente a los educandos sin tener que recurrir a la música tradicional como único medio de garantizar el conocimiento y el respeto de la alteridad.

\section{6.- REPERCUSIÓN SOBRE LA COMUNIDAD EDUCATIVA}

Durante los últimos años del siglo XX se empezó a tomar consciencia de la importante situación pluricultural del país. Situación que llevó a replantearse las necesidades educativas del alumnado de las diferentes etapas educativas obligatorias, que debían ser adecuadamente resueltas para lograr una situación de convivencia pacífica y enriquecedora, finalmente.

Ante esto, el profesorado comenzó a considerar qué tipo de actuaciones serían más recomendables. Así, surgen las numerosas propuestas de tipo multicultural y las poquitas de tipo intercultural, actuaciones didácticas en las que el intercambio y la interacción grupal debían ser las características principales. En el caso que nos ocupa, las actividades musicales propuestas se basaron en las características de la educación intercultural porque se pretendía garantizar la convivencia y el diálogo entre culturas, y no una simple coexistencia que maquillase la problemática latente. Es decir, que se estaba tratando de demostrar cómo el proceso de enseñanza/aprendizaje musical si partía del trabajo cooperativo y colaborativo con una música que fusionase lo pop (cercano al alumnado) con los elementos tradicionales de distintas zonas del mundo, podía permitir la interculturalidad en el aula.

Así el objetivo de este artículo quedaba conseguido, puesto que los educandos aprendieron a tomar las actividades con música "pop-mestiza" como base para el entendimiento cultural necesario para una construcción compartida, gracias al intercambio de ideas y a la autorreflexión; al tiempo que adquirían los aprendizajes conceptuales musicales específicos. Este tipo de actividades que se propusieron se caracterizaban por el carácter cooperativo, por la necesidad del diálogo, que permitirá al docente educar en la tolerancia (Olaya, 2002) hacia "el otro", imprescindible para garantizar la interculturalidad.

Se puede afirmar sin ningún ápice de duda, que en todo el currículo educativo de Secundaria no hay ninguna una asignatura más completa que la Música para desarrollar una perspectiva intercultural, lo que explica el tomarla como punto de encuentro para el trabajo de la interculturalidad. De hecho, autores como Díez e Ibarretxe (2008) la consideran el referente más importante en la configuración de la identidad juvenil; y, añádase que debido a cada uno de sus momentos característicos como son la audición, la interpretación, la composición o la improvisación. Todos ellos hacen que esta asignatura garantice la formación en valores interculturales y que fomente el diálogo, el intercambio y la reflexión cultural, que pueden considerarse los motores de la educación intercultural; aunque no debe olvidarse que el uso de esta música moderna tan marcada por las influencias externas no occidentales, son las que posibilitan el desarrollo de situaciones interculturales.

Ahora bien, un planteamiento intercultural de la asignatura de música repercutirá positivamente sobre la comunidad educativa y, por extensión, en la sociedad en la que está inmersa. Pero, sólo si se tiene en cuenta que no tiene porqué insistirse en el estudio de la música tradicional de cualquier parte del mundo como único medio de educar interculturalmente a través de la música, ya que no debe caerse en mostrarla como única representante de la identidad de un pueblo (Martín, 2009). Es decir, que con las diferentes propuestas musicales incluidas que partían de la música moderna (cierto aire pop con reminiscencias rítmicas, melódicas e instrumentales no occidentales) se pudo 
comprobar que al alumnado la única música que no le resulta extraña es ésta, aquella que escuchan en televisión, en la radio, etc.; de modo que, un acercamiento a otras culturas a través de un análisis de la música moderna supondría mayores garantías de éxito en el tratamiento de la diversidad cultural. Esto es, si se utiliza la música moderna desde un análisis comparado de características culturales resultará más fácil acercarse al alumnado de otras culturas, además de trabajar los valores interculturales.

Ante estas consideraciones, se puede decir que la música de Macaco respondió a estas directrices: son canciones que potencian su creatividad, que les permiten conectar áreas diferentes de conocimiento (Gómez Cantero, 2005) y, precisamente, esa idea de conexión de diferentes elementos es lo que se necesita para desarrollar una actitud intercultural en el alumnado. Siguiendo esa línea de interconexión, casi todas las canciones cuya letra incide en una temática de queja o protesta ante la realidad de la sociedad española, e incluso cuyos vídeos musicales se convierten en reivindicaciones políticas y sociales, muestran ritmos y giros melódicos de diferentes culturas del mundo, en un intento de mostrar cómo la letra está relacionada con la música y cómo se pueden establecer relaciones con otras músicas del mundo. De manera que, se puede afirmar que Macaco tiene una música muy adecuada para trabajar interculturalmente en las aulas pluriculturales españolas, ya que acerca otras culturas y permite conocer la propia, al tiempo que garantiza el proceso de enseñanza/aprendizaje de conceptos específicos musicales.

Las actividades mostraron cómo ese uso de la música moderna para educar interculturalmente podía mejorar la percepción del otro y de sus características, siempre desde músicas conocidas realmente por el alumnado, como son aquellas canciones que escuchan a diario en la radio o la televisión. Garantiza un acercamiento a otras músicas desde un punto de “audición” más próximo, e invita a reflexionar sobre la propia cultura desde combinaciones sonoras más atractivas al alumnado que la música tradicional que, en la mayoría de los casos, les resulta desconocida. De modo que, la música actual puede convertirse en ese instrumento educativo intercultural que evite caer en prácticas multiculturales estereotipadas, porque ese tipo de tratamientos folcloristas de la diferencia cultural debe perder fuerza ante otras actividades (Cobo, Motos, García y Moral, 2009) como las presentadas en este artículo.

Esta música y estas actividades musicales propuestas contribuirán a la adquisición de la interculturalidad gracias a que resultan más cercanas, a que invitan a la reflexión, a un tratamiento comparado de sus contenidos por parte del docente, y promoverán cambios conductuales (Jauset y Abad, 2012) que es básicamente lo que se persigue para garantizar la convivencia, imprescindible para la sociedad democrática (Vila, 2009).

\section{7.- EVALUACIÓN}

La evaluación de las diferentes actividades realizadas perseguía comprobar el grado de adquisición de la competencia intercultural, que tan necesaria se consideró para garantizar la convivencia entre culturas. Sobre todo, se consideró más importante la evaluación del comportamiento del alumnado fuera del aula, es decir, las diferencias a la hora de relacionarse entre el alumnado de nuestra clase y el de aquellas otras del centro.

Se plantearon debates al finalizar cada actividad centrados en recoger sus propias reflexiones sobre las actividades, su aprovechamiento y aquello que habían aprendido sobre "el otro". Principalmente, se quería observar la evolución de sus ideas entre una actividad y la siguiente; al tiempo que, mediante la observación en las guardias de patio, se comprobaba las diferencias en las relaciones entre culturas entre el alumnado de unas aulas y el de la nuestra.

La competencia intercultural no está considerada exactamente un elemento que deba "obtenerse" al finalizar el curso y, por tanto, evaluarse como tal. Sin embargo, es imprescindible para que la convivencia entre culturas sea una realidad en el aula. De modo que, todas las actividades musicales debían orientarse en esta dirección y, por tanto, era el elemento principal que debía evaluarse aunque fuese mediante la observación directa como si se tratase de alumnado de Infantil.

Esta evaluación permitió comprobar cómo el propio profesorado necesitaba una formación continua en este campo intercultural para que se fuese consciente de que, igual que la cultura, la 
formación didáctica debe evolucionar con la sociedad. Igual que la cultura, la didáctica no es un "producto" acabado y los docentes necesitan ser formados para que puedan comprender lo que implica el fenómeno migratorio (Cobo, Motos, García y Moral, 2009) y, por tanto, la educación del alumnado hijo de inmigrantes.

Este proceso citado de evaluación mediante debates reflexivos con el alumnado permitieron conocer el grado de interculturalidad alcanzado en el aula y reorientar determinadas actividades para que fomentasen el trabajo de estos valores interculturales con actividades mucho más reflexivas, sobre todo, de cara a garantizar la continuidad en la siguiente etapa educativa (Bachillerato), en la que estas cuestiones parecen desaparecer debido a la presión de la superación de la PAU como objetivo principal.

\section{8.- REFERENCIAS}

Arenas, L. (2009). La educación en valores en la asignatura de Historia de la Música. Temas para la Educación: revista digital para profesionales de la enseñanza, 4, 1-9.

Arévalo, A. (2009). Importancia del folklore musical como práctica educativa. Revista electrónica de LEEME, 23, 1-14.

Azorín, C. M. \& Vicente, G. (2012). Opus Solidaridad: Trío para música, educación y valores. Espiral. Cuadernos del profesorado [en línea] 10(5), 78-86. Disponible en: http://www.cepcuevasolula.es/espiral/articulos/ESPIRAL_VOL_5_N_10_ART_7.pdf

Bosch, M ${ }^{\mathrm{a}}$ C. (2002). Valores y creencias del profesorado de secundaria sobre algunos aspectos de la educación. Revista Electrónica Interuniversitaria de Formación del Profesorado [en línea], 5 (2). Disponible en: http://aufop.com/aufop/uploaded_files/articulos/1227714648.pdf. [Consulta: 2013, 28 de enero].

Bravo, R. \& De Moya, M ${ }^{a}$ V. (2006). Multiculturalidad musical para las aulas del siglo XXI. Ensayos, 21, 131139.

Céspedes, E. (2009). Vivir mejor, educación por medio del arte: construcción del sentido artístico en la escuela. San José: Coordinación Educativa Cultural Centroamericana.

Cobo, M $M^{a}$ F., Motos, M $M^{a}$ A., García, A. J., \& Moral, G. (2009). Análisis de las actividades realizadas en los proyectos de interculturalidad desarrollados en las provincias de Almería y Málaga. Espiral. Cuadernos del Profesorado [en línea], 2(3), 104-110. Disponible en: http://www.cepcuevasolula.es/espiral/articulos/ESPIRAL_VOL_2_N_3_ART_12.pdf

Conejo, P. A. (2012). El valor formativo de la música para la educación en valores. DEDiCA. Revista de Educaçao e Humanidades, 2, 263-278.

Díaz, M. \& Ibarretxe, G. (2008). Aprendizaje musical en sistemas educativos diversificados. Revista de Psicodidáctica, 13(1), 97-110.

Díez, P. (2009). Educación artística: lugar de vecindad para el desarrollo humano. Pulso, 32, 123-145.

García-Durán, J. A. (2001). Educar en la globalización. El programa del progreso material. ESE: Estudios sobre Educación, 1, 37-42.

Gómez Cantero, J. A. (2005). Educación y creatividad. ESE: Estudios sobre Educación, 9, 79-105.

Gómez Quintana, R. (2011). Música étnica, música intercultural un acercamiento en la Educación Primaria, [en línea]. Disponible en: http://eduinnova.es/monografias2011/mar2011/musica.pdf. [Consulta: 2013, 28 de enero].

Herrera, L., Cremades, R. \& Lorenzo, O. (2010). Preferencias musicales de los estudiantes de Educación Secundaria Obligatoria: influencia de la educación formal e informal. Cultura y Educación, 22 (1), 3751.

Jauset, J. A. \& Abad, E. (2012). La música y los valores de la paciencia y la constancia. Artseduca, 3, 6-9.

Leiva, J. J. (2011). La educación intercultural en una encrucijada de caminos: reflexiones pedagógicas para la construcción de una escuela intercultural. Espiral. Cuadernos del Profesorado [en línea], 4 (7), 43-56. Disponible en: http://www.cepcuevasolula.es/espiral/articulos/ESPIRAL_VOL_4_N_7_ART_5.pdf

Martín, R. (2009). Integración intercultural en el aula de música: conceptos clave. Revista Ibero-Americana de Estudos em Educaçao [en línea], 4 (2). Disponible en: http://seer.fclar.unesp.br/iberoamericana/article/viewFile/2778/2514. [Consulta: 2013, 28 de enero]. 
Navas, L., Iborra, G. \& Sampascual, G. (2007). Las metas académicas de los estudiantes de ESO en la clase de música. Revista de Psicodidáctica, 12(1), 131-142.

Olaya, Ma D. (2002). Educación en valores: la tolerancia. Ensayos: Revista de la Facultad de Educación de Albacete, 17, 219-236.

Riviére, G. H. (2009). La museología. Curso de museología/Textos y testimonios. Madrid: Akal.

Sanfeliu, A. \& Caireta, M. (2005). La música como instrumento de educación para la paz. Bellaterra: Escola de Cultura de Pau, Facultad de Ciencias de la Educación.

Touriñán, J. M. \& Longueira, S. (2010). La música como ámbito de educación. Educación “por” la música y educación “para” la música. Teoría de la Educación, 22, 151-181.

Venturi, L. (2004). Historia de la crítica de Arte. Barcelona: Random House Mondadori.

Vicente, G. (2010). El libro de texto en educación musical. Espiral. Cuadernos del Profesorado [en línea], 3(5), 30-35. Disponible http://www.cepcuevasolula.es/espiral/articulos/ESPIRAL_VOL_3_N_5_ART_3.pdf

en:

Vila, E. (2005). Educar en valores, educar por los derechos humanos: la reflexión y el diálogo como estrategias mediadoras para la prevención y resolución de conflictos. Revista Iberoamericana de Educación, 37(5), $1-12$.

Vila, E. (2009). Educar para la tolerancia, educar para la convivencia. Espiral. Cuadernos del Profesorado en $\begin{array}{llll}\text { línea], } & 2(4), & \text { 43-47. } & \text { Disponible }\end{array}$ http://www.cepcuevasolula.es/espiral/articulos/ESPIRAL_VOL_2_N_4_ART_4.pdf

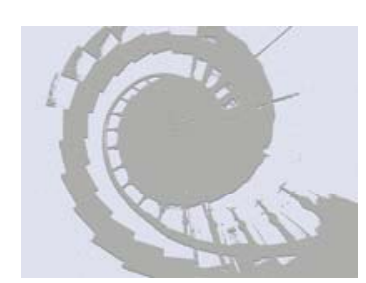

